\title{
Analysis of the porphyrin content of fluorescent pus by absorption spectrophotometry and high performance liquid chromatography
}

\section{J. S. BRAZIER}

Anaerobe Reference Unit, Public Health Laboratory, Luton and Dunstable Hospital, Lewsey Road, Luton, Beds, $\angle U 4 O D Z$

Summary. Extracts of 19 samples of pus which showed red fluorescence with ultraviolet light were screened for the presence of porphyrins by absorption spectrophotometry. All those which showed spectra typical of metal-free porphyrins were analysed by high performance liquid chromatography to identify the porphyrins present. These were predominantly the di-carboxylic porphyrins, deuteroporphyrin and mesoporphyrin, and another which was thought to be pemptoporphyrin. This combination matched those reported previously in normal stools. Protoporphyrin IX was shown not to be the most common fluorescent pigment in pus and was never present alone. However, the di-carboxylic porphyrins may be produced by bacterial metabolism of its labile vinyl side-chains. Black-pigmented bacteroides (the melaninogenicus group of Bacteroides spp. and Porphyromonas spp.) were isolated from $12(63 \%)$ of the 19 pus samples; these may produce protoporphyrin IX by the demetallation of haem.

\section{Introduction}

Records of the phenomenon of red fluorescence from the application of ultra-violet (UV) light in vivo date from 1924 when Policard ${ }^{1}$ reported on the fluorescent properties of experimentally induced necrotic sarcomas in rats. He attributed the fluorescence to haematoporphyrin and showed histologically that microbial infection was present, although no bacteriological studies were performed. The first in-vitro study that implicated bacterial action as a source of porphyrin and a cause of red fluorescence was also published in 1924 by the German worker Kammerer. ${ }^{2} \mathrm{He}$ incubated faeces in a broth medium containing blood, and noted that fluorescence frequently developed after 2-6 days. He suggested that spore-forming organisms were probably involved, as the phenomenon could be reproduced if a boiled faecal suspension was used, and that some kind of "helper bacteria" were apparently needed. Ronchese et $a l .{ }^{3}$ reported red fluorescence of the necrotic, ulcerated surfaces of squamous cell epitheliomas, of necrotic adenocarcinomas of the breast, and of facial fibrosarcoma. This was the first study that attempted to relate fluorescence to the bacterial flora: Streptomyces albus was isolated

Received 15 Jan. 1990; accepted 23 Feb. 1990. from one of the cases and was found to produce a similar fluorescence in vitro on blood-containing media. Sharvill, ${ }^{4}$ in a study of the fluorescent properties of various malignant and non-malignant conditions, reasoned that the red fluorescence was probably due to bacterial action on blood or the products of tissue breakdown.

From these studies, links were established between bacterial action and porphyrin fluorescence in vivo, but apart from Kammerer, who had the perspicacity to suggest that the formation of red fluorescence indicated the presence of obligate anaerobes, and that looking for such fluorescence would indicate that putrefaction and decay were present, anaerobes were largely overlooked as a cause of porphyrin fluorescence. It was not until 1969 that Myers et al. ${ }^{5}$ re-established the importance of obligate anaerobes in the process when they observed brilliant red fluorescence in cutaneous ulcers and on dressings from abdominal abscesses from which they isolated an anaerobic organism, Bacteroides melaninogenicus.

Since the validation of Kammerer's prophecy, the simple demonstration of the red fluorescence of porphyrins in clinical material, by the exposure of samples of pus and wound dressings to long-wave UV light, has been employed successfully as a rapid method for the presumptive diagnosis of anaerobic 
bacterial involvement in sepsis. ${ }^{6,7}$ Shah et al. ${ }^{8}$ analysed the porphyrins produced by $B$. melaninogenicus in vitro as predominantly protoporphyrin IX, and medical microbiologists have largely assumed that the red fluorescence of pus is due predominantly to this porphyrin, although no modern analytical methods have been employed.

High performance liquid chromatography (HPLC) is a recognised tool for porphyrin analysis of biological materials such as blood, urine and faeces in the laboratory diagnosis of suspected porphyric disease, ${ }^{9}$ and the present study sought to analyse accurately the porphyrin content of fluorescent clinical material with modern methods. The fluorescent pigments were extracted from pus specimens and subjected to absorption spectrophotometry and HPLC analysis. Bacterial culture was used to screen fluorescent specimens for known fluorescent organisms such as members of the black-pigmented bacteroides group (i.e., the melaninogenicus group of Bacteroides spp. and Porphyromonas spp.).

\section{Materials and methods}

\section{Samples of pus}

Samples that exhibited red fluorescence under longwave $(365 \mathrm{~nm})$ UV light in a darkened room were collected. They were from various clinical sites, mainly aspirated pus from surgical patients at the Luton and Dunstable Hospital; a few samples were kindly sent by post from other Public Health Laboratories. The relevant data were recorded, and the samples were examined immediately or stored in the dark at $-70^{\circ} \mathrm{C}$ and thawed at room temperature before examination. Some nonfluorescent samples were included for comparison.

\section{Extraction of porphyrin from pus}

Porphyrin was extracted by the acid-ether method of Lockwood et al.,$^{10}$ for faeces, which provides an extract that is free of interfering carotenoid and chlorophyll pigments.

Equal volumes $(1 \mathrm{ml})$ of pus and concentrated $\mathrm{HCl}$ were agitated on a vortex mixer for $10 \mathrm{~s}$ in a centrifuge tube; $3 \mathrm{ml}$ of diethyl ether and $3 \mathrm{ml}$ of distilled water were added, and the tube was agitated again. After centrifugation at $3000 \mathrm{rpm}$ for $5 \mathrm{~min}$, the ether supernate and the cellular interface layer were discarded, and the aqueous deposit was passed through a $0 \cdot 2-\mu \mathrm{m}$ membrane filter. The filtrate was deemed suitable for spectrophotometric analysis.

\section{Spectrophotometry}

A minimum of $1 \mathrm{ml}$ of filtrate was pipetted into a quartz cuvette and placed in a Lambda 5 UV-VIS Spectrophotometer (Perkin Elmer). Scanning absorption spectrophotometry from $650 \mathrm{~nm}$ to $380 \mathrm{~nm}$ was performed, and the absorption spectrum recorded.

\section{High performance liquid chromatography (HPLC)}

Further extraction of specimen. In an Eppendorf centrifuge tube, $0.5 \mathrm{ml}$ of the filtrate was mixed with $0.75 \mathrm{ml}$ of a mixture of equal volumes of dimethyl sulphoxide (BDH) and trichloroacetic acid $30 \%$, to render the filtrate free of protein. After agitation for $10 \mathrm{~s}$, the tube was centrifuged at $12000 \mathrm{rpm}$ for $10 \mathrm{~min}$. If red fluorescence was seen in the supernate, $20 \mu \mathrm{l}$ of this extract was injected into the HPLC column for analysis.

HPLC analysis was performed with a dual pump Gilson HPLC System fitted with an IBM computer as system controller and data handler. The fluorescence detector had an excitation band filter of $310-410 \mathrm{~nm}$ and an emission band filter of $585-650 \mathrm{~nm}$. The column was a Microsorb $15-\mathrm{cm} \mathrm{C18}$ reversed phase HPLC column (Anachem Ltd, Luton).

Separation of porphyrins was achieved by gradient elution with solvent A ( $1 \mathrm{M}$ ammonium acetate, Sigma, pH 5.16, and HPLC grade acetonitrile $10 \%$ ) and solvent B (HPLC grade acetonitrile $10 \%$ in methanol).

HPLC gradient profile. The volume ratio of solvents A:B was $60: 40$ initially, and changed linearly over a 30min period to $0: 100$, after which the solvents reequilibrated to the initial conditions over a 1 -min period.

A porphyrin standard, containing a mixture of free acid uroporphyrin $I$, and 7,6, and 5 carboxylporphyrins, coproporphyrin I, mesoporphyrin IX and protoporphyrin IX (Porphyrin Products Ltd), was prepared in $3 \mathrm{M} \mathrm{HCl}$ and analysed by the above procedure. A separate standard of pure deuteroporphyrin IX hydrochloride was used.

The retention times of peaks were recorded after the injection of 20- $\mu 1$ samples of pus-extract or standard.

\section{Culture of bacteria from pus}

Samples of pus were cultured for the presence of blackpigmented strains of the genera Bacteroides and Porphyromonas (formerly asaccharolytic pigmented Bacteroides spp. ${ }^{11}$ ) on Fastidious Anaerobe Agar (Lab M Ltd, Bury) incorporating horse blood $6 \%$, and the same medium made selective by the addition of neomycin sulphate $70 \mathrm{mg} / \mathrm{L}$. A disk containing $5 \mu \mathrm{g}$ of metronidazole was placed on the streaked inoculum, and plates were incubated in an anaerobic cabinet at $37^{\circ} \mathrm{C}$ for up to 5 days. Cultures were screened each day under UV light for red-fluorescent colonies and in daylight for black colonies typical of the melaninogenicus group of Bacteroides or Porphyromonas spp.

\section{Results}

Three samples of non-fluorescent pus and 19 of fluorescent pus were examined. 
Table. Porphyrin content of 19 fluorescent and three non-fluorescent samples of pus analysed by HPLC

\begin{tabular}{|c|c|c|c|c|c|c|c|}
\hline \multirow[b]{2}{*}{ Pus sample } & \multirow[b]{2}{*}{ Fluorescence } & \multicolumn{6}{|c|}{ Porphyrins detected in pus samples } \\
\hline & & uro- & copro- & deutero- & unknown* & meso- & proto- \\
\hline P3 P9 & + & - & - & + & - & - & - \\
\hline P35 P52 & + & - & + & + & - & - & - \\
\hline P29 & + & + & - & + & - & - & - \\
\hline Pl & + & - & + & + & + & - & + \\
\hline P10 & + & - & + & - & - & - & - \\
\hline P14 & + & - & - & + & + & - & - \\
\hline P19 & + & - & + & + & - & - & + \\
\hline P20 P54 & + & - & - & + & - & + & + \\
\hline P21 P25 & + & - & - & - & - & + & - \\
\hline P30 & + & - & - & + & + & + & + \\
\hline P33 P34 P44 & + & - & - & + & + & + & - \\
\hline P38 & + & - & + & + & + & + & - \\
\hline P50 & + & - & - & + & + & - & + \\
\hline P4 P47 P53 & - & - & - & - & - & - & - \\
\hline
\end{tabular}

+ , Present; -, absent.

* The retention-time of this unknown porphyrin suggests that it may be pemptoporphyrin (see text).

\section{Bacterial culture}

Of the 19 fluorescent samples, cultures of blackpigmented Bacteroides or Porphyromonas spp. were grown from $12(63 \%)$. Negative culture may have resulted from bacterial death during transport. No isolates of pigmented or fluorescent bacteroides were made from the three non-fluorescent pus samples.

\section{Absorption spectrophotometry}

All extracts of fluorescent pus displayed an absorption spectrum which contained a large "Soret" absorption band at c. $400 \mathrm{~nm}$, typical of metal-free porphyrins (fig. 1). Usually, a much smaller peak at $c$. $550 \mathrm{~nm}$ was present also. Nonfluorescent pus extracts gave no absorption bands over the same scanning range.

\section{HPLC analysis of porphyrin content}

The table summarises the chromatograms of the porphyrin analyses of 19 fluorescent and three nonfluorescent pus samples. Porphyrin peaks were identified by comparing their column retention times with those of the free-porphyrin standards. Representative chromatograms of three fluorescent pus extracts, from a urethral abscess, pyosalpinx and faecal fistula, are shown in figs 2-4.

Of the 19 fluorescent samples, protoporphyrin IX was present in only six, never alone. Deuteroporphyrin was the most common, being found in

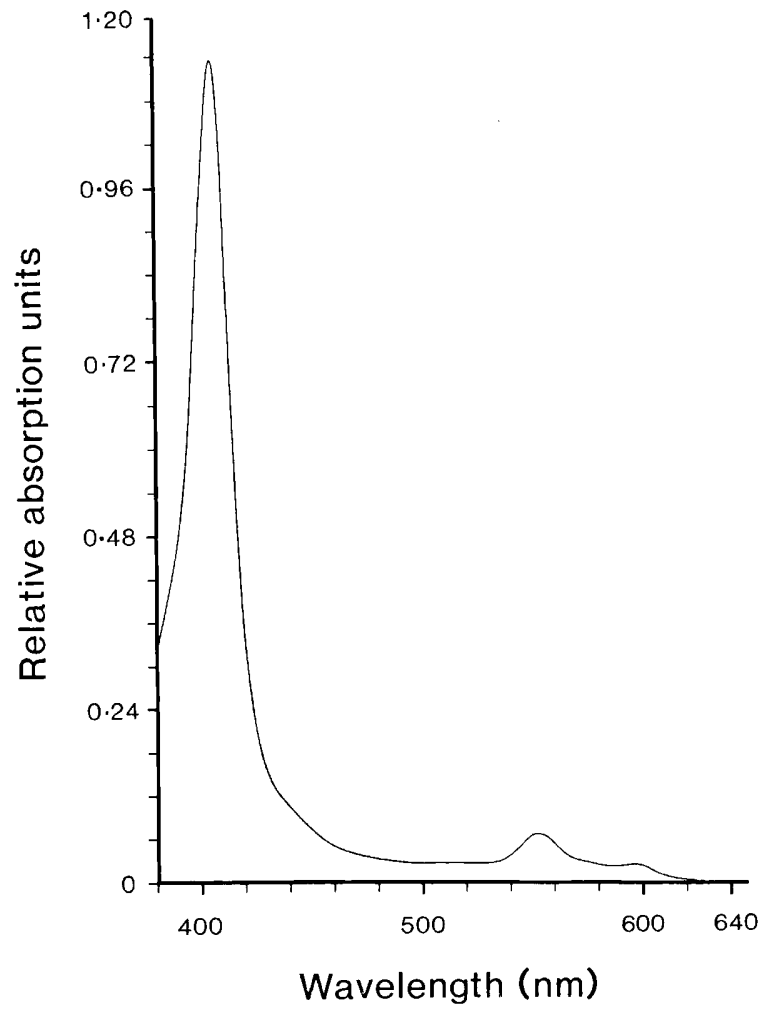

Fig. 1. Absorption spectrum of a typical extract of fluorescent pus, showing a large peak at $c .400 \mathrm{~nm}$ and a small one at $c$. $550 \mathrm{~nm}$. 


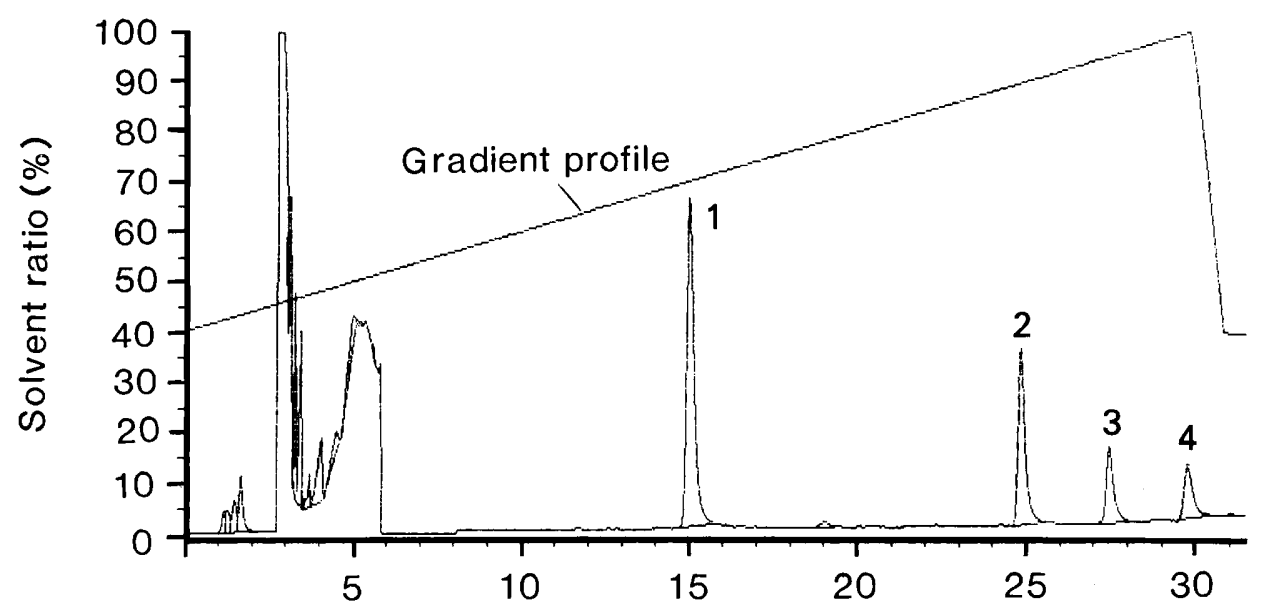

Time $(\min )$

Fig. 2. HPLC trace of extract of fluorescent pus P1 from a urethral abscess. The peaks were identified from their retention times, by computer, as coproporphyrin (peak 1), deuteroporphyrin (2), an unknown porphyrin (3) and protoporphyrin (4).

16; mesoporphyrin was present in nine, an unknown porphyrin peak between deutero- and mesoporphyrin appeared in eight, coproporphyrin in six and uroporphyrin in one. No porphyrins were found in the non-fluorescent pus samples.

\section{Discussion}

The results of HPLC analysis of the porphyrin content of fluorescent samples of pus showed that protoporphyrin IX was not the most common porphyrin in fluorescent pus, and was never present alone as the sole fluorescent pigment. This contrasts with earlier in-vitro analyses. ${ }^{8}$ The commonest porphyrins found in the present study were those of the dicarboxylic group-mesoporphyrin and deuteroporphyrin. Protoporphyrin IX is a labile structure with two vinyl side chains that are prone to bacterial degradation $;^{12}$ thus, protoporphyrin IX may become denatured to other porphyrins. Comparison of porphyrins previously reported in normal stools with those found in fluorescent pus in the present study is striking. French et $a l .^{12}$ identified five porphyrins in stools-copro-, deutero-, meso-, pempto- and proto-porphyrin IX. They speculated that protoporphyrin

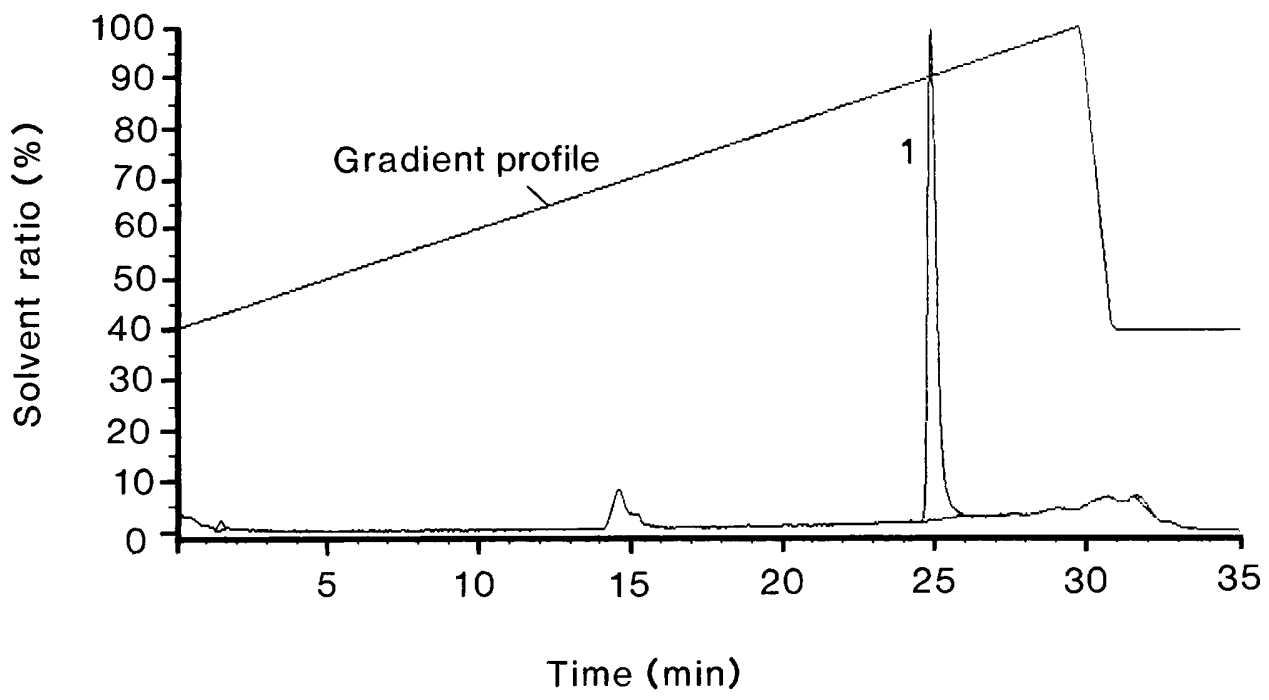

Fig. 3. HPLC trace of extract of fluorescent pus P3 from a pyosalpinx. The peak (1) was identified as deuteroporphyrin. 


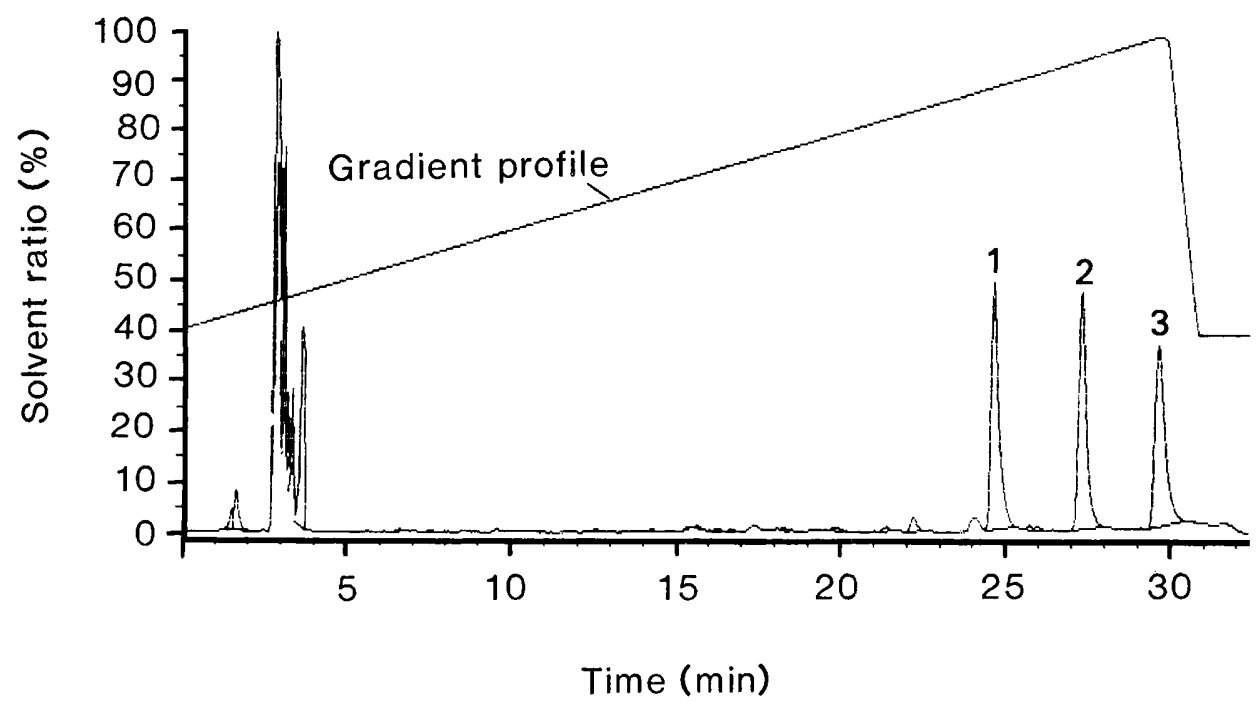

Fig. 4. HPLC trace of extract of fluorescent pus P33 from a faecal fistula. The peaks were identified as deuteroporphyrin (1), an unknown porphyrin (2) and mesoporphyrin (3).

IX was probably converted into the more stable meso-, deutero- and pempto-porphyrins by bacterial degradation.

From the present results with pus it is tempting to suggest that the unknown porphyrin peak lying between meso- and deutero-porphyrin is pemptoporphyrin, but this remains unproven because a commercial standard of pemptoporphyrin is not available. Another possibility is harderoporphyrin, previously found only in the Harderian eye gland of rodents. ${ }^{13}$

It is most likely that the porphyrins in pus originate mainly via the demetallation of haem. There is no obvious exogenous supply of haem in pus as may be found in the gut in dietary meat residue or from gastrointestinal bleeding, but there is an endogenous source of haem, because pus contains extravasated red cells and polymorphs and, like the gut, has a heavy microbial load. As in faeces, the porphyrins in pus (except coproporphyrin and uroporphyrin) are not those of the haem biosynthetic pathway, but appear to originate from protoporphyrin IX which is formed when iron $\left(\mathrm{Fe}^{++}\right)$is removed from haem. Therefore, it seems logical to suppose that the component required to initiate the formation of protoporphyrin IX would have the ability to remove the iron from haem.

\section{REFERENCES}

1. Policard A. Étude sur les aspects offerts par des tumeurs experimentales examinées à la lumière de Wood. $C R$ Soc Biol Paris 1924; 91 : 1423-1424.

2. Kammerer $\mathbf{H}$. Uber das durch darmbakterian gebildte
Following the work of Myers et al. ${ }^{5}$ and Shah et $a l .{ }^{8}$ it is widely held by medical microbiologists that the black-pigmented group of gram-negative anaerobes effects this removal of iron, although the mechanism by which protoporphyrin IX is produced from haem is unknown. The present study demonstrated members of this group in $63 \%$ of fluorescent pus samples. In the $37 \%$ of samples from which black-pigmented anaerobes were not isolated, the organisms may have died in transit or on freeze-thawing, or indeed other components of the bacterial flora may have caused the fluorescence. This warrants further study because Brazier ${ }^{14}$ demonstrated that other anaerobes can produce protoporphyrin IX from haem in vitro. As pure protoporphyrin was shown not to be the sole fluorescent moiety of pus, it is likely that other components of the flora are involved in modifying protoporphyrin to other dicarboxylic porphyrinsmeso-, deutero- and possibly pempto-porphyrin.

I am grateful to Dr A. Deacon, Department of Clinical Chemistry, Northwick Park Hospital, Harrow, and to Dr C. K. Lim, Clinical Research Centre, Harrow, for their help and advice with HPLC methods, to the staff of the Haematology Department, Luton and Dunstable Hospital, for the use of their spectrophotometer, and to Dr A. T. Willis for his support.

porphyrin und de bedetung der porphyprobe fur die buerteilung der darmfaulnis. Dtsch Arch F Klin Med $1924 ; 145: 257-284$.

3. Ronchese F, Walker BS, Young RM. The reddish orange fluorescence of necrotic cancerous surfaces under the Wood light. AMA Arch Dermatol 1954; 69: 31-42. 
4. Sharvill D. On the red fluorescence of certain ulcers under Woods light. Trans St Johns Hosp Derm Soc 1955; 34: 32-36.

5. Myers MB, Cherry G, Bornside BB, Bornside GH. Ultraviolet red fluorescence of Bacteroides melaninogenicus. Appl Microbiol 1969; 17: 760-762.

6. Willis AT. Anaerobic bacteriology: clinical and laboratory practice, 3rd edn. London, Butterworths. 1977.

7. Finegold SM, George WL (eds). Anaerobic infections in humans. San Diego, Academic Press. 1989: 120

8. Shah HN, Bonnett R, Mateen B, Williams RA. The porphyrin pigmentation of subspecies of Bacteroides melaninogenicus. Biochem J 1979; 180: 45-50.

9. Lim CK, Li FM, Peters TJ. High performance liquid chromatography of porphyrins. $J$ Chromatogr 1988; 429: 123-153.

10. Lockwood WH, Poulos V, Rossi E, Curnow DH. Rapid procedure for fecal porphyrin assay. Clin Chem 1985; 31: 1163-1167.

11. Shah HN, Collins MD. Proposal for reclassification of Bacteroides asaccharolyticus, Bacteroides gingivalis, and Bacteroidesendodontalis in a new genus, Porphyromonas. Int J Syst Bacteriol 1988; 38: 128-131.

12. French JM, England MT, Lines J, Thonger E. Separation of ether-extractable fecal porphyrins by counter-current distribution. Arch Biochem Biophys 1964; 107: 404-418.

13. Jones CW, Hoffman RA. Porphyrin concentration of the hamster (Mesocricedus auradus) Harderian gland: effects of incubation with delta-aminolevulinic acid and various hormones. Int J Biochem 1976; 7: 135-139.

14. Brazier JS. A note on ultra-violet red fluorescence of anaerobic bacteria in vitro. J Appl Bacteriol 1986; 60: $121-126$ 